\title{
Analysis of Catalytic Potential of a New Heterogeneous Catalyst in the Preparation of Biodiesel
}

\author{
Fernando Storti $^{\mathrm{a}}$, Marcos A.L. Nobre ${ }^{\mathrm{b}}$, Silvania Lanfredi ${ }^{\mathrm{c}}$ \\ Laboratório de Compósitos e Cerâmicas Funcionais- LaCCeF, Faculdade de Ciências e \\ Tecnologia - FCT, Univ Estadual Paulista - UNESP, P.O Box 467, CEP 19060-900, \\ Presidente Prudente-SP, Brazil.
}

afernando.storti@hotmat.com, bnobremal@fct.unesp.br, 'silvania@fct.unesp.br

Keywords: Double Perovskite, Biodiesel, Heterogeneous Catalysis.

\begin{abstract}
In this work was investigated the catalytic potential of a new heterogeneous catalyst of stoichiometry $\mathrm{Ca}_{0.5} \mathrm{~K}_{0.5} \mathrm{TiCu}_{0.25} \mathrm{O}_{3}$, with double perovskite structure, in the preparation of biodiesel via ethylic route. The catalyst was synthesized by the Polyol Modified method and characterized by X-ray diffraction, scanning electron microscopy, infrared spectroscopy and gas chromatography coupled to mass spectrometry. The investigation of the catalytic activity was carried out from transesterification reaction of commercial soybean oil with ethyl alcohol. Single-phase and crystalline powders related to the $\mathrm{CaTiO}_{3}$ phase were obtained with an average crystallite size at around $17.25 \mathrm{~nm}$. The new catalyst showed high efficiency for the production of biodiesel via heterogeneous catalysis with a yield at around $97 \%$, with reaction time of 8 hours at $78^{\circ} \mathrm{C}$ and $15 \%$ of catalyst mass in relation to the soybean oil mass.
\end{abstract}

\section{Introduction}

Currently, a large number of studies have been performed on oxides of perovskite structures in the search of new materials for technological, scientific and industrial applications [1,2]. These oxides present versatile structures able of generating a large family of solids. The simple $\mathrm{ABO}_{3}$ perovskite structure can be described as a three-dimensional cubic network of corner-sharing BO6 octahedra, where the A-cation occupies the cavity between eight corner-sharing octahedral units. However, when one or more cations are substituted in simple $\mathrm{ABO}_{3}$ perovskites lead to a large class of materials known as double perovskites, $\mathrm{AA}^{\prime} \mathrm{BB}^{\prime} \mathrm{O}_{6}$ or $\mathrm{A}_{2} \mathrm{BB}^{\prime} \mathrm{O}_{6}$. These perovskites exhibit properties similar to the simple perovskite as multiferroics, which show both ferromagnetic and ferroelectric properties simultaneously. In addition, the $\mathrm{A}_{2} \mathrm{BB}^{\prime} \mathrm{O}_{6}$ double perovskite have been investigated because of their interesting magnetic properties, since strong ferromagnetism, large ferroelectric polarization, giant magnetoresistance and half-metallicity, until magnetoelectricity evidences, may have many applications in the emerging industry of spintronics $[3,4]$. While $\mathrm{A}_{2} \mathrm{BB}^{\prime} \mathrm{O}_{6}$ perovskites are investigated due their magnetic and magnetoresistance properties, $\mathrm{AA}^{\prime} \mathrm{BB}^{\prime} \mathrm{O}_{6}$ perovskites have been investigated by their catalytic and dielectric properties $[5,6]$. The optimization of parameters to obtaining of biodiesel, from $\mathrm{Ca}_{0.5} \mathrm{~K}_{0.5} \mathrm{TiCu}_{0.25} \mathrm{O}_{3}$ nanostructured particles synthesized by polyol modified method, were carried out from the quantification of residual glycerol based on reaction time, temperature and catalyst concentration.

\section{Experimental}

Synthesis

$\mathrm{Ca}_{0.5} \mathrm{~K}_{0.5} \mathrm{TiCu}_{0.25} \mathrm{O}_{3}$ nanostructured powder was synthesized by a modified polyol method $[7,8]$. Starting reagents for the synthesis via chemical route were nitric acid, $\mathrm{HNO}_{3}(99,5 \%$ Reagen), calcium carbonate, $\mathrm{CaCO}_{3}\left(99,0 \%\right.$ Reagen), potassium carbonate, $\mathrm{K}_{2} \mathrm{CO}_{3}(99,0 \%$ Reagen), ethylene glycol, $\mathrm{HOCH}_{2} \mathrm{CH}_{2} \mathrm{OH}\left(98,0 \%\right.$ Synth), titanium oxide, $\mathrm{TiO}_{2}(99,5 \%$ Reagen) and copper oxide $\mathrm{CuO}_{2}$ (99,0\% Reagen). The reagents were dissolved in nitric acid with continuous stirring in a beaker. Then $100 \mathrm{ml}$ of ethylene glycol was added. The solution was heated at $90^{\circ} \mathrm{C}$, promoting the decomposition of $\mathrm{NO}_{3}$ group, similar to the process developed in the Pechini method [9]. After the 
polyesterification reaction, a polymeric gel is obtained. This polymer is maintained in the beaker being subjected to a primary calcination in a box-type furnace. The heating cycle was carried out via a two-step calcination starting from room temperature. In the first step, the temperature was increased with a heating rate of $10^{\circ} \mathrm{C} / \mathrm{min}$ up to $150^{\circ} \mathrm{C}$. At this point, the temperature was kept constant during $30 \mathrm{~min}$. In the second step, the temperature was increased to $300^{\circ} \mathrm{C}$ and kept constant for $1 \mathrm{~h}$. Then the furnace was cooled by nitrogen flux with a constant rate of $500 \mathrm{ml} / \mathrm{min}$. The process results in partial polymer decomposition to form a resin. This material was deagglomerated (350 mesh) in an agate mortar and then called of a precursor powder. $\mathrm{Ca}_{0.5} \mathrm{~K}_{0.5} \mathrm{TiCu}_{0.25} \mathrm{O}_{3}$ single-phase powders, with high crystallinity degree, was obtained with calcination of precursor powder at $950^{\circ} \mathrm{C}$ during $3 \mathrm{~h}$ under integral oxygen atmosphere with a flux rate of $300 \mathrm{ml} / \mathrm{min}$.

The transesterification reaction was performed using commercial refined soybean oil and absolute ethanol. In a round bottom flask connected to a reflux condenser containing $30 \mathrm{ml}$ of oil was added percentages between 5 and $15 \mathrm{~mol} \%$ of catalyst and $72 \mathrm{ml}$ of ethanol. The reaction mixture was kept under reflux and vigorous stirring for 8 hours at $78{ }^{\circ} \mathrm{C}$. The biodiesel obtained was characterized by gas chromatograph mass spectrometry (Shimadzu GC-MS QP2010 Plus).

\section{Results and Discussion}

\section{Structural Characterization by X-ray Diffraction}

Fig. 1 shows the diffraction pattern and the scanning electron microscopy image (inset) of the $\mathrm{Ca}_{0.5} \mathrm{~K}_{0.5} \mathrm{TiCu}_{0.25} \mathrm{O}_{3}$ precursor powder calcined at $950{ }^{\circ} \mathrm{C}$.

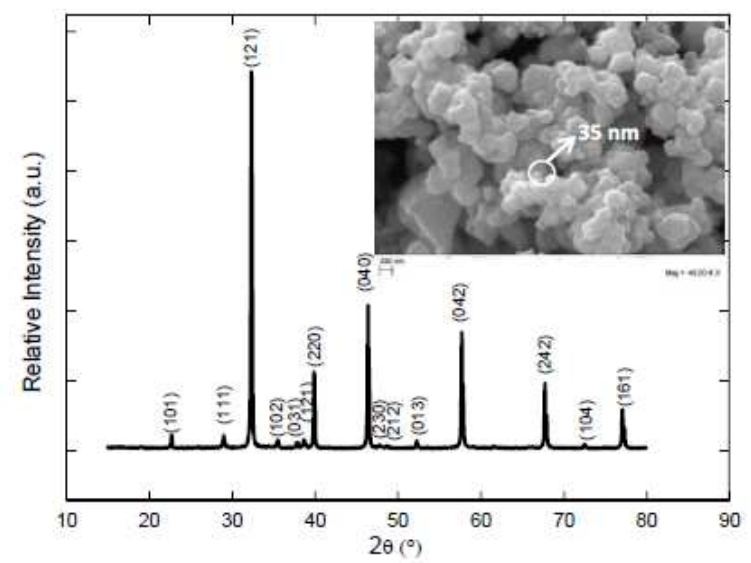

Fig. 1: XRD diffraction pattern and SEM of the $\mathrm{Ca}_{0.5} \mathrm{~K}_{0.5} \mathrm{TiCu}_{0.25} \mathrm{O}_{3}$ precursor powder calcined at $950{ }^{\circ} \mathrm{C}$ for $3 \mathrm{~h}$.

The $\mathrm{Ca}_{0.5} \mathrm{~K}_{0.5} \mathrm{TiCu}_{0.25} \mathrm{O}_{3}$ nanostructured powder exhibited only a set of diffraction lines ascribed to the cubic symmetry, which was identified from the JCPDS card number 22-0153. From XRD diffraction pattern, the crystallite sizes $(D)$ was derived by Scherrer's equation using the Jade 8 Plus software [10]:

$$
D=\frac{k \cdot \lambda}{\beta \cdot \cos \theta}
$$

where $\beta$ is the broadening of the diffraction line measured at half of the maximum intensity, $\lambda$ is the wavelength $(\mathrm{Cu}-\mathrm{K} \alpha), \theta$ is the Bragg angle for a given diffraction, and $\mathrm{k}$ is a constant, which is in general equal to 0.9 for powders. The crystallite size was equal to $17.25 \mathrm{~nm}$. The SEM image shows that the size of primary particles should be between 30 and $50 \mathrm{~nm}$ because coalescence actuation secondary particles with sizes ranging from $100 \mathrm{~nm}$ were formed. The difference between the crystallite size calculated using X-ray diffraction data and the particle size obtained by SEM was due to the fact that the particles were composed of several crystalline domains, which were observed by X-ray diffraction, while the whole particle was observed in SEM. 


\section{Analysis of the Catalytic Potential}

The catalytic tests with the $\mathrm{Ca}_{0.5} \mathrm{~K}_{0.5} \mathrm{TiCu}_{0.25} \mathrm{O}_{3}$ nanopowder from ethylic transesterification reaction of commercial soybean oil were carried out using $15 \%$ in mass of catalyst in ratio to the soybean oil mass, with reaction time of 8 hours. Fig. 2 shows the FR-IR spectra of the commercial soybean oil, biodiesel and biodiesel obtained in the presence of $\mathrm{Ca}_{0.5} \mathrm{~K}_{0.5} \mathrm{TiCu}_{0.25} \mathrm{O}_{3}$ catalyst.

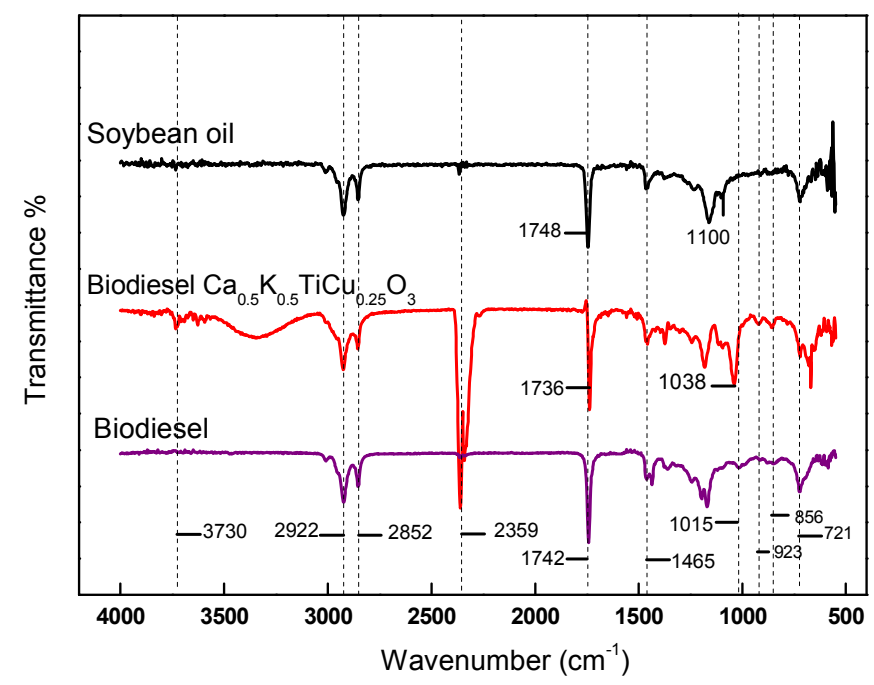

Fig. 2: FT-IR spectra of commercial soybean oil, pure biodiesel and biodiesel obtained in the presence of $\mathrm{Ca}_{0.5} \mathrm{~K}_{0.5} \mathrm{TiCu}_{0.25} \mathrm{O}_{3}$ catalyst.

From the infrared spectra shown in Fig. 2 can be observed a chemical similarity between triglycerides from soybean oil and the reaction product, composed of ethyl esters. The spectra show weak absorption bands in the region of $3730 \mathrm{~cm}^{-1}$ attributed to the vibration of symmetrical stretching of hydroxyl groups of the glycerol, indicating that a small fraction of this product would be present in the biodiesel spectrum. Bands with medium intensities centered at $1748 \mathrm{~cm}^{-1}$ and $1736 \mathrm{~cm}^{-1}$ can be associated with the antisymmetric stretching of the functional grouping of esters $\left(V_{\text {as }}\left[\mathrm{CH}_{2}(\mathrm{C}=\mathrm{O}) \mathrm{OCH}_{3}\right]\right)$ [11]. In addition, small displacement of these bands to lower wavenumber was observed in the biodiesel spectra. This phenomenon is identified when there is a replacement of the glycerol by ethyl radical, that is considered an indicative of biodiesel formation [12]. In biodiesel spectra can be observed, besides bands present in the soybean oil spectra, the appearance of a new band of medium intensity between $1038-1042 \mathrm{~cm}^{-1}$. These absorption bands are attributed to the antisymmetric stretching of coupled bond $\left(V_{a s} \mathrm{C}-\mathrm{O}-\mathrm{C}\right)$ of esters of primary alcohols $[13,14]$ indicating that occurred the transesterification reaction of the soybean oil to biodiesel. Another observation in the biodiesel spectra are the bands at $923 \mathrm{~cm}^{-1}$ and $856 \mathrm{~cm}^{-1}$ with low intensity attributed to the symmetrical stretching of carbon-oxygen bond ( $\left.V_{s} \mathrm{C}-\mathrm{O}-\mathrm{C}\right)$ of ethyl esters.

These bands were not observed in the triglycerides spectra of soybean oil, because they are characteristic of ethyl esters [14].

Quantification of Glycerol Mass

For quantification of glycerol masses obtained and of fractions termed biodiesel was investigated the transesterification reaction, ranging the catalyst mass in $5 \%, 10 \%$ and $15 \%$ in ratio to the mass of the oil with reaction time of 8 hours. The data obtained are listed in Table 1.

Table 1: Mass of oil, of glycerol and of the fractions termed biodiesel, obtained from the transesterification reaction, ranging the $\mathrm{Ca}_{0.5} \mathrm{~K}_{0.5} \mathrm{TiCu}_{0.25} \mathrm{O}_{3}$ catalyst mass in $5 \%, 10 \%$ and $15 \%$ in ratio to the mass of the oil.

\begin{tabular}{ccccc}
\hline catalyst & \% catalyst & oil (g) & glycerol (g) & biodiesel (g) \\
\hline $\mathrm{Ca}_{0.5} \mathrm{~K}_{0.5} \mathrm{TiCu}_{0.25} \mathrm{O}_{3}$ & $5 \%$ & 27.30 & 1.98 & 26.60 \\
$\mathrm{Ca}_{0.5} \mathrm{~K}_{0.5} \mathrm{TiCu}_{0.25} \mathrm{O}_{3}$ & $10 \%$ & 27.05 & 2.37 & 26.50 \\
$\mathrm{Ca}_{0.5} \mathrm{~K}_{0.5} \mathrm{TiCu}_{0.25} \mathrm{O}_{3}$ & $15 \%$ & 27.10 & 3.36 & 26.75 \\
\hline
\end{tabular}


From Table 1 can be observed that the $\mathrm{Ca}_{0.5} \mathrm{~K}_{0.5} \mathrm{TiCu}_{0.25} \mathrm{O}_{3}$ catalyst with $15 \%$ in mass showed higher activity in transesterification reactions than lower percentages of catalyst. Thus, in order to optimize the transesterification reaction, using $15 \%$ in mass of catalyst, was investigated the reaction time with removal of aliquots during the catalytic tests with times between 1, 2, 3, 4, 6 , 8,12 and 24 hours. The increase of reaction time showed major catalytic activity. This can be observed with gradual increase in the amount mass of glycerol, with 8 hours of reaction. Above this time there was not a significant increase in the amount of glycerol formed.

Analysis of the Biodiesel by Gas Chromatography

Fig. 3 shows the chromatogram of the ethyl biodiesel obtained with $15 \%$ in mass of catalyst and reaction time of 8 hours.

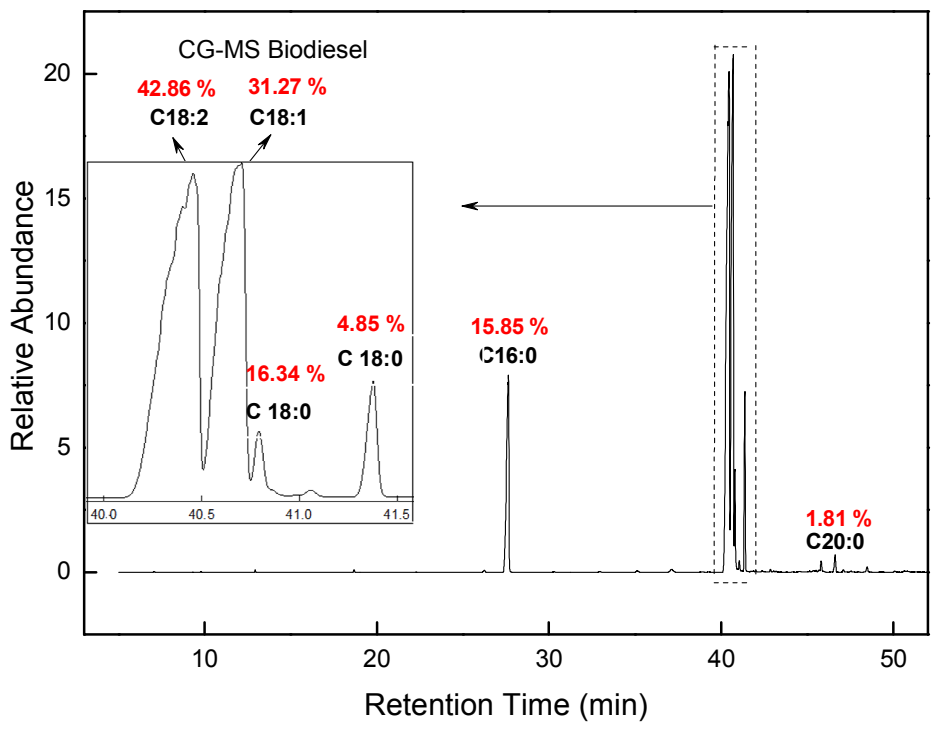

Fig. 3: Chromatogram of the biodiesel.

Fig. 3 shows the peaks related to the ethyl ester obtained from the transesterification reaction of soybean oil with the $\mathrm{Ca}_{0.5} \mathrm{~K}_{0.5} \mathrm{TiCu}_{0.25} \mathrm{O}_{3}$ catalyst. Chromatographic analysis of these esters led to the determining of three regions of higher specific elution. The first region of elution with medium intensity can be observed from 27 minutes and represents the ester ethyl palmitate (C16:0), lower molecular weight. The second region of high intensity (magnified inset), at around 40 minutes, corresponds to the elution region of three esters of molecular weight very close, and identified as: ethyl linoleate (18: 2$)$, ethyl oleate $(18: 1)$ and ethyl stearate $(18: 0)$, respectively. The last elution region of lower intensity, at around 47 minutes, represents the ester ethyl arachidate (20:0), higher molecular mass. The analysis by gas chromatography showed that the transesterification reaction, in presence of the $\mathrm{Ca}_{0.5} \mathrm{~K}_{0.5} \mathrm{TiCu}_{0.25} \mathrm{O}_{3}$ catalyst, presented high yield. The sum of the integration of peak areas showed a total of ethyl esters at around $97 \%$. The retention times of the monitored ions and the percentages $(\% \mathrm{~m} / \mathrm{m})$ of each one of the esters identified of the biodiesel are shown in Table 2.

Table 2: Determination and quantification of total esters of biodiesel by gas chromatography in the presence of $\mathrm{Ca}_{0.5} \mathrm{~K}_{0.5} \mathrm{TiCu}_{0.25} \mathrm{O}_{3}$ catalyst.

\begin{tabular}{|c|c|c|}
\hline Esters & Retention Time (min) & $\% \mathrm{~m} / \mathrm{m}$ \\
\hline Palmitate $\quad(\mathrm{C} \mathrm{16:0)}$ & 0.25 & 15.85 \\
\hline Linoleate $\quad$ (C 18:2) & 0.27 & 42.86 \\
\hline Oleate $\quad(\mathrm{C} 18: 1)$ & 0.22 & 31.27 \\
\hline (C 18:0) & 0.10 & 4.85 \\
\hline Arachidate (C 20:0) & 0.15 & 1.85 \\
\hline Total Esters & - & 96.68 \\
\hline
\end{tabular}


According to the Technical Regulations of the National Petroleum Agency ANP, 1/2008, the content of B100 esters should be at least $96.5 \%$. In this sense, the biodiesels obtained in this work via ethylic route are in accordance with the requirements of current legislation [15].

\section{Conclusions}

Polyol Modified method was adequate for obtaining of crystalline nanopowders with stoichiometry $\mathrm{Ca}_{0.5} \mathrm{~K}_{0.5} \mathrm{TiCu}_{0.25} \mathrm{O}_{3}$. The analysis by gas chromatography identified and quantified the ethyl esters present in the biodiesel as: ethyl palmitate (C16: 0), ethyl linoleate (18: 2), ethyl oleate (18:1), ethyl stearate (18: 0) and ethyl arachidate (20:0). Gas chromatograph mass spectrometry analysis identified the molecular weight of the main esters present in the biodiesel. From the integration of peaks area by chromatography was possible to calculate the yield of the transesterification reaction. The yield of $96.68 \%$ was obtained with $15 \%$ in mass of catalyst with reaction time of 8 hours at $78^{\circ} \mathrm{C}$.

\section{Acknowledgments}

The authors are grateful to the Brazilian research agencies: FAPESP, CNPq and UNESP/PROPe for financial support.

\section{References}

[1] B. Saparov, D.B. Mitzi: Chem. Rev. Vol. 116 (2016), p. 4558.

[2] S. Keav, S.K. Matam, D. Ferri, A. Weidenkaff: Catalysts Vol. 4 (2014), p. 226.

[3] Z. Fang, K. Terakura, J. Kanamon: Materials Vol. 4 (2011), p. 153.

[4] J. W. Li, P. M. Haney : Phys. Rev. B, Vol. 93 (2016), p. 155432.

[5] M.C. Viola, J.A. Alonso, J.C. Pedregosa, R.E. Carbonio: Eur. J. Inorg. Chem Vol. 8 (2005), p. 1559.

[6] A. Grimaud, K.J. May, C.E. Carlton, Y.L. Lee, M. Risch, W.T. Hong, J. Zhou, Y. Shao-Horn: Nat. Commun. Vol. 4 (2013), p. 2439.

[7] S. Lanfredi, C. Darie, F.S. Bellucci, C.V. Colin, M.A. L. Nobre: Dalton Trans. Vol. 43 (2014), p. 10983.

[8] S. Lanfredi, I.A.O. Brito, C. Polini, M.A.L. Nobre: J. Appl. Spectrosc. Vol. 79 (2012), p. 254.

[9] M.P. Pechini: U.S. Patent, No. 3.330 .697 (1967).

[10] Jade 8 Plus, XRD Pattern Processing and Identification Program, Materials Data, Inc. 19952007.

[11] R.M. Silverstein, F.X. Webster, D.J. Kiemle: Spectrometric Identification of Organic Compounds. (John Wiley \& Sons New York, 1998), p. 503.

[12] E.W. Castilho-Almeida, H.F. Santos, A.M. Miranda, A. Jorio, E.H.M. Ferreira, C.A. Achete, R.A.S.Z. Armond, C.P.A. Anconi, W.B. Almeida: Quím. Nova Vol. 35 (2012), p. 1752.

[13] L.L.N. Guarieiro, A.C. Pinto, P.F. Aguiar, N.M. Ribeiro: Quim. Nova Vol. 31 (2008), p. 421.

[14] D.L. Pavia, G.M. Lampman, G.S. Kris: Introduction to Spectroscopy A Guide for Students of Organic Chemistry. (Sauders College Publishing 2a .ed. USA, 1996).

[15] ANP Agência Nacional do Petróleo, Gás Natural e Biocombustíveis, Resolução ANP No 14, De 11.5.2012 - DOU 18.5.2012. 
Reproduced with permission of copyright owner. Further reproduction prohibited without permission. 